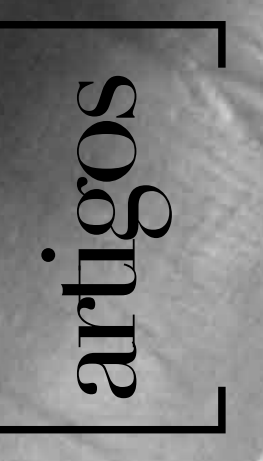




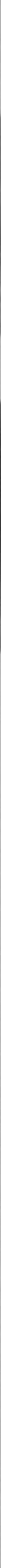




\title{
Pedro Weingärtner, pintor da vida moderna e a moda nos museus
}

\author{
Pedro Weingärtner, modern life painter \\ and fashion at museums
}

[resumo] A presente reflexão busca estabelecer relações de produtividade entre o artigo de Athos Damasceno Ferreira, Apontamentos para o estudo de uma indumentária do Rio Grande do Sul, de 1957, já abordado anteriormente, com as narrativas visuais do pintor teuto-rio-grandense Pedro Weingärtner, como cronista da indumentária do fim do século XIX. Assim, busca-se estabelecer uma ponte entre a história da arte acadêmica e tradicional, documentada pelos museus, e a história da indumentária local, ainda carente de coleções materiais. Defende-se o estudo dos acervos pictóricos para a compreensão de uma história da moda regional, como forma de representação (mimese) possivel.

\section{palavras-chave}

história da arte; história da indumentária; arte e indumentárias; museus; Pedro Weingärtner.

[abstract] This reflection aims to do productivity relations between Athos Damasceno Ferreira's article Apontamentos para o estudo da indumentária do Rio Grande do Sul, wrote in 1957, that we had pointed earlier, with visual narratives from Pedro Weingärtner, an german-rio-grandense painter, as chronist of garment of the XIX's finals. Therefore, we search to establish a bridge between academical and traditional Art History, safe in the museums, and local garment history, still poor in material collections. We defend the study of pictural resources to comprehend regional history of fashion, as possible representation (mimesis).

[keywords] art history; garment history; art and garment; museum; Pedro Weingärtner. 


\section{A fazenda e o museu}

Resultado do momento histórico específico de sua fundação e voltado para a documentação e a exposição da arte rio-grandense primordialmente, mas não apenas, o Museu de Arte do Rio Grande do Sul (MARGS) foi inaugurado em 1954. Seu patrono e idealizador, o italiano Ado Malagoli, pintor e professor da Escola de Belas Artes de Porto Alegre, deu origem ao atual Instituto de Artes da Universidade Federal do Rio Grande do Sul, onde trabalho. Sua abertura ocorre em pleno desenvolvimento do Modernismo, tardio, no Estado e é considerado o principal museu de arte da "provincia" mais ao sul do Brasil, com cerca de 3 mil obras de artistas locais, nacionais e internacionais em seu acervo. 0 museu é um órgão estatal, vinculado à Secretaria da Cultura do Estado do Rio Grande do Sul (SEDAC), e hoje está abrigado no prédio da antiga Fazenda Pública (atualmente a Receita Federal), obra do arquiteto alemão Theo Wiederspahn, projetado em 1911.

Desde 1978, o MARGS ocupa essa edificação, quando a Fazenda foi transformada em Museu, com reserva técnica, equipe de historiadores, conservadores e ainda uma importante biblioteca de arte, dentro de seu centro de documentação. Além disso, o museu, desde os anos 1950, já tinha, entre suas preocupações, a formação de mediadores, trabalho pioneiro e fundamental iniciado pela professora Cristina Balbão (ver GOMES, 2013) e que segue em curso na atualidade, recebendo alunos de diversas instituições e graduações, formando atuadores educativos que atingirão o público geral, mas principalmente 0 escolar.

Recentemente, entretanto, o museu, que tradicionalmente aborda suportes e temas mais acadêmicos, tem-se aberto a exposições com curadorias menos convencionais, evidenciando algum interesse pelo design e pela indumentária; além de viabilizar iniciativas correlatas, como a promoção de palestras e cursos sobre esses temas, anteriormente tidos como secundários, colaterais ou menores.

Mesmo assim, apesar desse grande desejo de renovação, as iniciativas recentes careceram, no meu entendimento, de um tratamento adequado à questão têxtil, que lá apareceu mais como exemplo de possibilidades estéticas do que como obra em si, como na exposição intitulada Geografias da Criação [Arte, Moda, Design], com trabaIho curatorial de Ana Zavadil, que aconteceu entre 4 de setembro e 16 de novembro de 2014. Mais do que a atenção à especificidade dos materiais e suas caracteristicas de "utilidade" ou de "arte", a mostra mesclou diversas linguagens fora dos suportes tradicionais, sendo os têxteis e as roupas apresentados em meio a objetos como fogões antigos, que seriam o exemplo de "design", também ele uma linguagem não tradicional, lá exibida.

Ou seja, a abertura, ou concessão, como se queira, foi feita, e isso é bastante positivo, mas sem um cuidado maior em se estabelecer as especificidades de cada meio ou linguagem, como se tudo aquilo que não é arte convencionalmente abordada na categoria da "grande arte" e em seus suportes - a saber: pintura, gravura e escultura - pudesse ser agrupado em uma categoria dita "outras linguagens".

Não fosse esse momento apenas, tipo de "critério" semelhante foi mantido em mostra posterior, dentro da última edição da Bienal do Mercosul, ao colocar lado a lado obras de Flavio de Carvalho, lole de Freitas, Arthur Bispo do Rosário, Lygia Clark e outros artistas que criaram e/ou lançaram mão de objetos vestíveis, sem nenhum tipo de contextualização de cada obra.

Seria desejável, e mesmo necessária, outra abordagem e critérios igualmente outros calcados na pesquisa especifica do tratamento museal e curatorial que vem sendo dado às questões de naturezas têxteis e indumentárias de maneira geral, conforme os trabalhos recentes de Rafaela Norogrando $(2013,2014)$. 
Também é digno de nota o debate desenvolvido por Maria Claudia Bonadio e a comunidade do Colóquio de Moda, em 2012, sobre o lugar da moda e da indumentária nos museus, bem como a sua artificação. Resultado parcial de uma pesquisa de pós-doutoramento junto ao acervo do Museu de Arte de São Paulo Assis Chateaubriand (Masp), a historiadora refletiu, em artigo, sobre essas questões ao encontrar um setor intitulado Coleções Diversas, entre as demais coleções, constante, entre outros objetos, de roupas e têxteis. Boa parte desse acervo ganhou corpo de lá para cá, consistindo na muito recente exposição Arte na Moda: Coleção MASP RHODIA, que teve lugar no referido museu entre 23 de outubro de 2015 e 14 de fevereiro de 2016.

Portanto, parece que boa parte das dúvidas e/ou reflexões levantadas pela autora sobre questões de artificação e musealização dessas coleções, especificamente, pode ter sido posta ainda mais em evidência, ou mesmo "resolvida", em função da dimensão da mostra, aproximando daquilo que Diana Crane (2011) desenvolve em seu livro Ensaios sobre moda, arte e globalização cultural, no que se refere à mistura entre alta cultura e cultura.

Mas, voltando às questões como a do MARGS, parece-me que, para que a moda, a indumentária e o têxtil possam ser introduzidos em um museu cuja trajetória é histórica e ainda mais convencional, é necessária uma abordagem quiçá mais didática e mesmo esquemática, para que o público tenha possibilidades de se apropriar dessas novas linguagens, anteriormente "inexistentes" em seu imaginário referente às exposições de arte.

Ou seja, o público frequentador desse tipo de museu, talvez recém-acostumado à arte contemporânea e todo o estranhamento questionador do próprio espaço museal, devesse ser introduzido às questões da indumentária e à moda como possibilidades representativas da arte em suas novas acepções e no debate todo que isso implica, o debate mesmo da arte e do sistema das artes na contemporaneidade.

Ainda que saibamos da intenção da equipe do museu em questão em constituir uma ponte mais aprofundada com a história da indumentária, a exemplo de recentes iniciativas como as relatadas, entre as quais palestras e cursos promovidos pela Associação de Amigos do MARGS, parece pertinente pensar que a principal via de diálogo com a história da indumentária e da moda no museu esteja já em seu acervo, na cultura visual e material representada em sua coleção de arte, em telas e esculturas ainda pouco exploradas pelo caminho expositivo mais tradicional.

\section{As imagens, as palavras e os tecidos}

Segundo o historiador inglês Peter Burke, em Testemunha ocular (2005), as imagens são o que torna possivel, muitas vezes, a nossa aproximação com a cultura material. Quando esta falta e não mais está à nossa disposição, é, por meio da imagem, que podemos recontá-la, ou melhor, acessá-la. Parte-se, portanto, da imagem "sobrevivente" que remete à existência do material que não nos resta mais. Além da possibilidade que a imagem propõe de ver o objeto em questão seja em uso, seja em seu entorno. A imagem do objeto retratado no conjunto de seu "meio ambiente" permite, inclusive, segundo Burke, que se compreenda melhor o papel do material em questão no momento em que ele ainda não é objeto de estudo, mas de uso.

Tal possibilidade não é posta desde já, quando da existência dessa cultura material per si: ela não se auto-explica sempre e a falta de referências que a acompanhem pode ser um complicador no estudo de um momento específico, de uma realidade, de uma época. Nesse sentido, o objeto não se coloca como "testemunha", mas talvez, apenas, como museu portátil que não contextualiza sua existência, a não ser sempre em cotejo com outras imagens e/ou objetos similares de uma época já identificada.

\section{De quando Athos Damasceno encontra Pedro Weingärtner}

A reflexão e a narrativa visual que aqui se propõem articulam pesquisas anteriores, igualmente voltadas para a compreensão de uma identidade do sul-rio-grandense, o gaúcho, como tipo social histórico, criado e recriado sucessivamente pela literatura do Rio da Prata e do Rio Grande do Sul, posteriormente, e pelas imagens que as ilustravam, ademais das obras pictóricas de artistas regionais. 
Anteriormente analisado em suas facetas literárias e historiográficas em meu De guaxos e de sombras (2010), resultado de tese doutoral (2006), teve-se como fonte principal os Apontamentos para o estudo da indumentária no Rio Grande do Sul (1957), de Athos Damasceno Ferreira, este artigo toma as imagens como reverberação das formas já encontradas literariamente.

No caso da coleção do Museu de Arte do Rio Grande do Sul, é em sua pinacoteca, principalmente, que se encontra um maior número de peças retratando uma história da moda do Rio Grande do Sul, de fins do século XIX ao decorrer do XX. Diversos pintores o fazem, mas, por razões pragmáticas, me dedicarei a analisar brevemente a obra de apenas um deles.

Como coleção histórica, a pinacoteca do MARGS é bastante reveladora: na busca pela construção de uma identidade plástica, há também a busca por uma identidade regional, tema tão recorrente na cultura rio-grandense, como muito bem argumentou Ruben Oliven no já clássico $A$ parte e o todo (2006). Este título, fundamental à compreensão dessa realidade rara e estranha, nos apresenta não o historiador, mas 0 antropólogo que desvenda as dificuldades de o Rio Grande do Sul se inserir na cultura nacional em vista de sua trajetória histórica anterior, voltada ao local e ao regional, articulado com o Rio da Prata - em suas lutas físicas e simbólicas com os castelhanos, uruguaios e argentinos - e a manutenção das fronteiras coloniais, imperiais e, mais tardiamente, nacionais. 0 Rio Grande do Sul é, pois, também integrante e fruto de uma outra comarca cultural que não apenas a brasileira, mas a platina (RAMA, 1982).

Segundo Susana Gastal, em importante estudo sobre a arte "no Rio Grande do Sul do Dezenove" (GASTAL, 2007, pp. 30-49), é na segunda metade do século,

em uma sociedade que se renovava, que nasceram os primeiros artistas gaúchos: Pedro Weingärtner (Porto Alegre, 1853), Augusto Luiz de Freitas (Rio Grande, 1868), Oscar Boeira (Porto Alegre, 1883), Affonso Silva (Porto Alegre, 1886), Leopoldo Gotuzzo (Pelotas, 1887), Libindo Ferrás (Porto Alegre, 1897) e João Fahrion (1898). (GASTAL, 2007, p. 39)

É com esses pintores radicados na capital Porto Alegre, ou em cidades com alguma tradição cultural, como Rio Grande e Pelotas, que, entre fins dos 1800 e meados dos 1900, encontraremos algumas dessas vozes que nos contam plasticamente como se desenvolvia o relato da cultura visual no Rio Grande do Sul, como o pintor descendente de alemães Pedro Weingärtner (1853-1929), conforme pontuam Ana Maria Albani de Carvalho (2008), Neiva Maria Fonseca Bohns (2008) e Paulo Cesar Ribeiro Gomes (2008), além da própria Susana Gastal (2007), em alguns trabalhos dedicados ao pintor publicados pela revista 19\&20, especializada em arte do século XIX, e no volume já citado.

Segundo o estudo de Gastal, é a produção de Weingärtner, primeira geração nascida no Brasil de uma família de imigrantes germânicos, que dominou a arte no Rio Grande do Sul em termos de pintura (GASTAL, 2007, pp. 40-41). Pedro era filho de uma familia com tradição gráfica significativa e que vem a fundar, em Porto Alegre, uma importante casa litográfica, onde o jovem Pedro realizaria as primeiras experiências artísticas, orientado pelos irmãos mais velhos. Segundo Susana Gastal,

com muita habilidade para desenho e pintura, o jovem Weingärtner voltou à Europa para aprimorar-se como artista. Estudou na Alemanha, esteve em Paris, e, por fim, passou a residir - por muitos anos - na Itália. Mas vinha periodicamente ao Brasil - e a Porto Alegre - para apresentar seu trabalho. Aproveitava para percorrer a cidade e o interior, fazendo anotações que serviriam para futuros trabalhos. Mesmo quando não visitava a região pessoalmente, Weingärtner se fazia presente enviando telas para que sua família as vendesse, ou fotos dos trabalhos 
que estava realizando, para conhecimento dos possiveis interessados na sua aquisição. (GASTAL, 2007, p. 41)

Com formação na tipografia da família e, posteriormente, com a acadêmica na Europa, Pedro encarna o típico artista visual da Belle Époque: viajava entre as principais capitais europeias, vestia-se com apuro, pintava cenas miticas vinculadas às visões de época da antiguidade clássica, conforme relata Athos Damasceno Ferreira em seu Artes plásticas no Rio Grande do Sul, compêndio até hoje basilar da história da arte sulina, publicado em 1971:

\begin{abstract}
Em setembro de 1897, por exemplo, os jornais da capital voltam a ocupar-se do artista, e o Correio do Povo registra: "A um dos nossos repórteres foram mostradas fotografias de admiráveis telas que estão fazendo sucesso e Roma (...)". As fotografias, a que as notícias aludiam, eram as dos quadros Frauta (sic) de Pan, A sentença de Páris e Um banho em Pompeia, fotos que, apesar de reproduzirem as telas apenas em preto e branco, davam, na opinião do crítico do jornal de Caldas Júnior, prova cabal do extraordinário mérito do seu autor. (FERREIRA, 1971, pp. 204-205)
\end{abstract}

Cumpre salientar, no estudo que faz sobre a arte produzida no Rio Grande do Sul daquela época, ou por artistas nascidos nessas terras, que Athos Damasceno dedica vinte páginas a Pedro Weingärtner. Nenhum outro artista recebe tanta atenção em seus escritos quanto ele: é o grande representante da "grande arte" durante o período em foco, além de ter se tornado professor na mais importante escola de Belas Artes do Brasil, a do Rio de Janeiro.

Em sua pesquisa que tem por fontes, majoritariamente, edições de época do jornal Correio do Povo, diário em que trabalhou até sua morte e em outros veículos de então, como 0 Mercantil, Athos Damasceno Ferreira aproveita a crítica da época para encontrar-se com a produção do pintor e tecer suas considerações:

\footnotetext{
Weingärtner pintará ainda muitas telas inspiradas em paisagens e costumes da Europa, principalmente da Itália. Mas a partir de então, o Rio grande do Sul será uma de suas mais constantes preocupações. Em 1893, por exemplo, afasta-se temporariamente da sua cátedra de Belas Artes do Rio de Janeiro e vem à Provincia. Após um giro de dois meses pelo Interior, traz para Porto Alegre um volumoso conjunto de manchas e apontamentos que destina a seis telas em esboço, conforme se vê da seguinte notícia publicada pelo Mercantil, de 25 de abril daquele ano: "Coube-nos ontem a satisfação de visitar o atelier do festejado artista Pedro Weingärtner, considerado uma das glórias do Brasil. De sua viagem pelo interior do estado trouxe impressões para seis quadros que ja se acham quase prontos - Cabana de camponeses rio-grandenses, Uma corrida de cavalos, Lavadeiras do Jacuí, Paisagem Ri-Grandense, Uma cena de charqueada e Atirador de bodoque à pedra. Esses quadros se recomendam já pelo belo efeito de luz, o colorido e a fidelidade com que se acham apanhados, já pelos tipos originais rio-grandenses. A Paisagem e A Corrida de Cavalos são dois quadros de primeira ordem, dignos de figurar e disputar prêmios nos salons parisienses. É merecedor dos mais altos encômios o nosso jovem conterrâneo que não deixa repousar sobre os louros conquistados e procura levantar cada vez mais o nome que granjeou entre as notabilidades europeias. (FERREIRA, 1971, p. 203)
}

Apesar do tom excessivamente laudatório, percebe-se, na crítica do jornal e no próprio Damasceno Ferreira, o apreço por Weingärtner e a consciência de seu papel 
como grande artista de sua geração. Pois é com Pedro Weingärtner e suas cenas tipicamente gauchescas do fim do século XIX que existe um registro mais histórico dos tipos, hábitos e costumes, conforme já salientado pelo mesmo Damasceno. Sua pesquisa de campo, a arqueologia que faz dos tipos sociais, assim como os estudos quase antropológicos, nos mostram um cronista preciosista em suas análises visuais, construídas como verdadeiras narrativas capazes de recontar a cena por ele assistida. Isso é visivel em telas como Tempora mutantur, de 1898, um óleo que faz parte do acervo do MARGS.

Trata-se de uma tela que mostra uma cena corriqueira na vida de um casal de camponeses. Neste retrato da vida que passa, do trabalho braçal dia após dia, o casal de agricultores vê o tempo inexorável. Suas roupas designam o trabalhador do campo, talvez não distante da cidade. Percebe-se que a indumentária aí documentada não se encontra com aquela esperada ao observar um verdadeiro gaúcho ou em uma prenda: a bombacha e o vestido a la andaluza, cheio de babados, conforme os estudos iconográficos de Vera Stédile Zattera (1995 e 1999) e legislados pelo Movimento Tradicionalista a partir de 1947. Ao contrário, o que se encontra é um traje ocidental comum, do fim do século XIX: uma camisa branca vestida com calça comprida e botas, sem esporas, visto que se trata de um homem da terra, não de um cavaleiro, como 0 tornado símbolo Laçador, de Antonio Caringi, escultor já falecido.

Trata-se de um bronze de 4,45 m de altura, confeccionado em 1954 e localizado em uma das entradas de Porto Alegre, próximo ao aeroporto. Em 1958, foi escolhido simbolo oficial da cidade, com uma representatividade muito expressiva ainda hoje. 0 modelo da obra foi o tradicionalista João Carlos Paixão Cortes, um dos ideólogos e pai fundador do Movimento Tradicionalista Gaúcho, juntamente com Luiz Carlos Barbosa Lessa e Glacus Saraiva.

0 mesmo ocorre com Estudo para "O bolicho", quando o pintor registra o interior de um estabelecimento comercial do fim do século XIX. Bolicho é o típico armazém de secos e molhados existente no Rio Grande do Sul. 0 estudo, em nanquim, permite visualizar o testemunho de Weingärtner como cronista do momento, no cotidiano das pessoas que no Estado viviam nos anos 1800.

Embora não sejam constantes do acervo do MARGS, gostaria de referir-me a outras telas do pintor, que nos auxiliam a compreender a sua narrativa. São elas: Chegou tarde!, de 1890, que faz parte do acervo do Museu Nacional de Belas Artes, e a tela Kerb, de 1892, pertencente a uma coleção particular.

A tela Chegou tarde! retrata uma cena de bolicho também. Dessa vez, não se trata de um estudo, mas do trabalho final. Na cena narrada, há o interior de um bolicho e a chegada de um caixeiro-viajante demasiadamente tarde: seu concorrente, vendendo tecidos, já exibia suas amostras à dona do estabelecimento. Ambos os caixeiros aparecem, dessa vez, vestidos comme il faut: bombacha e poncho. A cena, também nesse híbrido, espécie de armarinho da época, nos mostra o trabalho; homens e mulheres em seus labores e mesmo a figura de uma escrava com a sua indumentária costumeira, como apresentada por Athos Damasceno Ferreira em seu estudo.

De certa forma não causa muito estranhamento que justamente essa obra esteja exposta no grande museu estatal brasileiro de arte, e de arte acadêmica por excelência, o Museu Nacional de Belas Artes, no Rio de Janeiro: representa a imagem do gaúcho que se espera ver dentro e fora do território sul-rio-grandense. Representante legítimo do tipo social, o quadro serve como vitrina para uma visualidade que vem do sul, assim como uma identidade imediatamente reconhecida, conforme um de meus estudos anteriores (BOSAK, 2010). Não por acaso, a historiadora argentina Ruth Corcuera, especialista em têxteis latino-americanos, escolheu essa imagem para seu último livro, em fase de finalização.

Ademais de sua produção plástica, também nos chama a atenção o apreço que tem o pintor por sua própria aparência, em sua toalete, em um momento de pose, conforme nos denuncia seu retrato, sem data. 
É essa figura de dândi, artista que faz da sua própria vida a sua obra-prima, que nos aparece como responsável pela crônica visual dos costumes de uma terra que tem dono: o gaúcho. Mas a figura cosmopolita de Pedro, viajado e estudado na Europa, não deixa dúvidas de sua filiação: ele é um homem do mundo, um artista de sua época, distante até certo ponto, portanto, daquilo que representa, quem sabe mesmo um "dândi criollo", conforme pode sugerir um outro estudo (BOSAK, 2013). Seria este o arquétipo do artista moderno por excelência, aquele que inventa a si mesmo, inclusive pelo uso da indumentária, conforme postula Nicolas Bourriaud em Formas de vida (BOURRIAUD, 2011)?

Mas é na tela Kerb, de 1892, que se vê a indumentária vestida de moda, no Rio Grande do Sul do fim do século XIX, em uma típica reunião da colônia alemã, representativa de um outro grupo social, os colonos europeus, que vão sendo paulatinamente assimilados pela cultura local.

$\mathrm{Na}$ tela, a festa mescla histórias, etnias, identidades: roupas europeias, "da moda", a bombachas, xales espanhóis; chinocas, prendas e colonas em suas roupas domingueiras. A negra que espreita, com seus panos na cabeça, do lado de fora da casa, na janela, a festa para a qual não foi convidada. A festa acontece após a missa? É o aniversário do dono da casa?

Talvez, em termos de indumentária, seja a tela mais significativa de Weingärtner, já que dialoga com as diferentes culturas pelas quais ele passou em sua vida no Rio Grande do Sul e mesmo fora dele.

Teórico visual do hibridismo, é na narração dessas cenas corriqueiras que Weingärtner vai nos dando subsídios para a compreensão daquilo que não nos restou: 0 material que não guardamos ou que se desfez com a vida que o levou.

A arte de Pedro Weingärtner ao imitar e representar a vida fez mais: tornou possivel ao presente recontar o passado, na vida das formas e nas "formas de vida", como diria uma vez mais Bourriaud (2011), escolhidas para serem documentadas e, por isso mesmo, eternizadas.

\section{De quando Pedro Weingärtner encontra Lunara}

Lunara, Luiz do Nascimento Ramos, foi um fotógrafo amador de origem portuguesa que viveu em Porto Alegre entre 1864 e 1937 e é considerado um dos pioneiros da fotografia no Rio Grande do Sul.

Lunara, que era dono de um bolicho, o mesmo armazém de secos e molhados do Rio Grande do Sul retratado por Pedro Weingärtner, fotografava muito cenas do cotidiano: seu filho brincando de panelinhas e jogo de chá; em uma delas, sentado em um "troninho" travestido de príncipe, intitulada sugestivamente de Serviço inadiável.

Mas além dessas cenas da vida privada, Lunara também fotografou os primeiros negros libertos dos arredores de Porto Alegre, com suas roupas, seus pés descalços e cascorentos; a casinha de pau a pique, quase uma tapera, no sombreado das áreas possíveis do fim do século XIX da então periferia da cidade...

Lunara fotografou também crianças e as primeiras escolas; os uniformes e o passeio na rua. Mais além da vida urbana de uma ainda mais provinciana Porto Alegre, Lunara vai atrás de cenas pictóricas. E o que fotografa é quase uma revelação, uma surpresa: é um quadro de Pedro Weingärtner. Editadas, cenografadas ou não, as imagens testemunham um mundo e uma maneira de vê-lo com o olho mecânico, conforme o estudo de Alexandre Santos (1997).

E foi a busca pela história do olho mecânico e da fotografia no Rio Grande do Sul que levou a repórter fotográfica Eneida Serrano, no fim dos anos 1970, a buscar registros literalmente esquecidos em baús. Foi no baú do filho de Lunara que a jornalista descobriu a história da fotografia no Rio Grande do Sul: cópias e negativos revelando o nascimento de um artista antes invisivel. Descoberto apenas por seu amigo de cenas em comum, o pintor Pedro Weingärtner.

Lunara comparece aqui como artista enorme que foi e como "prova" de que a obra criativa de Weingärtner é também mimese e fidelidade de uma realidade dada pela lente e pelo olho do fotógrafo, conforme o lindo trabalho que disseca as imagens visuais e pictóricas criadas por ele, a dissertação de mestrado de Denise Stumvoll 
(2014). Mesmo em preto e branco, confirmamos as hipóteses de que as telas recriavam, mas ao mesmo tempo retratavam, com muita propriedade e "fidelidade" visual as cenas da vida "real":

Porto Alegre e seus arredores eram o cenário de suas fotos, lugares que naquela época permitiam que a composição das cenas que Lunara concretizava com a paciência e a precisão de um pintor. Foi amigo dos artistas plásticos Pedro e Miguel Weingärtner e com eles saiu muitas vezes para fotografar, resultando daí a semelhança de ambientes e de situações retratadas tanto pelos pintores como pelos fotógrafos. (SERRANO, 1979, p. 8.)

Se a história da arte é a grande fonte de uma história da indumentária e da moda é porque esses grandes artistas, à sua maneira, souberam tecer, em suas telas, por meio da cor e da linha, toda uma forma de ver e vestir o mundo que habitaram e que ainda nos habita.

\section{As imagens e as coisas, enfim}

Da memória material resta o registro visual de um verdadeiro historiador da moda: sem ele, como se veria aquilo que Athos Damasceno Ferreira (1957) nomeia, mas não registrou visualmente, nem referencia em termos documentais?

Nos apontamentos saborosos de Damasceno Ferreira (1957), temos o "perfume" e o colorido - ou mesmo a falta de cor - de uma indumentária trazida dos Açores el ou criada no que hoje é o Rio Grande do Sul, a partir do campo e pouco da vida na cidade. Entretanto, essa visualidade é toda imaginada: não temos uma única gravura nesse estudo, todo ele centrado naquilo que acaba sendo percebido apenas em nossa vontade de ver; sugerido pelas leituras que nos chegam em segunda mão.

Este artigo, "lendo" as imagens criadas por Weingärtner, reiteradas por Lunara, também ele um grande cronista visual, procura ver aquilo que não é óbvio. É a busca de uma resposta às perguntas visuais deixadas pelo estudo quase invisivel de Athos Damasceno Ferreira.

Por isso, agora se possa pensar que, quiçá, o primeiro estágio desse museu da indumentária e da moda que tanto queiramos já exista em sentido amplificado: embora os têxteis não estejam lá, as imagens estão. E com elas, todo o sentido de uma época, seu entorno, um contexto, um encontro: algo que, muitas vezes, o têxtil sozinho não consegue abarcar.

As pinturas - e as fotografias, como as de Lunara - nos contam toda uma história silenciada das roupas e das formas, dos jeitos e costumes que se perderam no tempo, mas ali estão: congeladas, rígidas, sólidas na materialidade de seus cenários. Evanescente é nossa memória, quando esquece ou não vê todo esse microuniverso contido numa imagem.

"Ut pictura poesis": na poesia muda do quadro, uma voz ecoa a memória das roupas que nossos antepassados viram ou vestiram, usaram e sofreram. As pessoas, tais como as roupas, não estão mais ali, mas o momento foi documentado por um tipo diferente de cronista: um "pintor da vida moderna", como diria Charles Baudelaire (2010).

0 que se defende aqui é que, assim como se utiliza a História da Arte para estudar grandes momentos da história da moda, em seus tempos mais remotos na cultura do Ocidente, no caso do Brasil, ou do Rio Grande do Sul, ou de quaisquer outros lugares em que os têxteis não nos restem, será na obra de alguns de seus grandes intérpretes que talvez possamos realmente nos reencontrar com as nossas ausências. 


\section{REFERÊNCIAS}

BAUDELAIRE, Charles. 0 pintor da vida moderna. Belo Horizonte: Autêntica, 2010.

BOHNS, Neiva Maria Fonseca. Realidades simultâneas: contextualização histórica da obra de Pedro Weingärtner. In: 19\&20, Rio de Janeiro, vol. III, n. 2, abr. 2008. Disponivel em: <http://www. dezenovevinte.net/artistas/artistas_nb_weingartner.htm>. Acesso em: 24 fev. 2016.

BONADIO, Maria Claudia. Moda é coisa de museu? In: COLÓOUIO NACIONAL DE MODA, 8, 2012, Rio de Janeiro. Anais. Disponível em: <http://coloquiomoda.com.br/anais/anais/8-Coloquio-de-Moda_2012/ GT06/ARTIGO-DE-GT/Moda_e_coisa_de_museu.pdf $>$. Acesso em: 2 mar. 2016.

BOSAK, Joana. Athos Damasceno e a escrita de uma história da indumentária no Rio Grande do Sul. Caxias do Sul: ABEPEM, 2014.

Dublinense, 2010

De guaxos e de sombras: um estudo sobre a identidade do gaúcho. Porto Alegre:

Dandies criollos: ideologia e indumentária no Rio da Prata dos Oitocentos. In: COLÓOUIO NACIONAL DE MODA , 8 2012, Rio de Janeiro. Anais. Rio de Janeiro: ABEPEM, 2012

BOURRIAUD, Nicolas. Formas de vida: a arte moderna e a invenção de si. São Paulo: Martins Fontes, 2011.

BURKE, Peter. Testemunha ocular. Bauru: EDUSC, 2005

CARVALHO, Ana Maria Albani de. A paisagem em Pedro Weingärtner (1853-1929): algumas hipóteses de trabalho. In: 19\&20, Rio de Janeiro, vol. 3, n. 3, jul. 2008. Disponivel em: <http://www.dezenovevinte. net/artistas/pw_amac_paisagem.htm>. Acesso em: 4 mar. 2016.

CATÁLOGO GERAL MUSEU DE ARTE DO RIO GRANDE DO SUL Vol. I. Organizado por Raul Holz. Porto Alegre: MARGS, 2013

CRANE, Diana. Ensaios sobre moda, arte e globalização cultural. São Paulo: SENAC-SP, 2011.

FERREIRA, Athos Damasceno. Apontamentos para o estudo da indumentária. In: Fundamentos da

Cultura Rio-Grandense. Porto Alegre: Faculdade de Filosofia, 1957.

Artes plásticas no Rio Grande do Sul (1755-1900). Contribuição para o estudo do processo cultural sul-rio-grandense. Porto Alegre: Editora Globo, 1971.

GASTAL, Susana. A arte no século XIX. In: GOMES, Paulo. Artes plásticas no Rio Grande do Sul: uma panorâmica. Porto Alegre: Lahtu Sensu, 2007, pp. 30-49.

GOMES, Paulo. Academismo e Modernismo: possiveis diálogos. In: BRITES, CATTANI, BULHÕES e GOMES. 100 anos de artes plásticas no Instituto de Artes da UFRGS. Três ensaios, pp. 17-76.

GOMES, Paulo César Ribeiro. Alguns comentários sobre Pedro Weingärtner. In: 19\&20, Rio de Janeiro vol. 3, n. 3, jul. 2008. Disponivel em: <http://www.dezenovevinte.net/artistas/pw_pg.htm>. Acesso em: 22 fev. 2016

NOROGRANDO, Rafaela; MOTA, João A.; PORTO, Nuno. 2013. Exposições museológicas. Narrativas, experiências e conexões, pp. 93-104. In: Sampaio, J.; Reis, M. Livro de Atas do UD12. $1^{\circ}$ encontro nacional doutoramentos em design, realizado em 14 de julho de 2012, Universidade de Aveiro, Portugal, p. 365. Disponivel em: <http://ud12.web.ua.pt/wp-content/uploads/2013/07/livro_de_atasUD12_ BR.pdf>. Acesso em: 23 fev. 2016.

NOROGRANDO, Rafaela; MOTA, João A. VEtA, um estudo de caso. Narrativas da cultura material de moda. In: COLÓOUIO DE MODA, 10, 2014, Caxias do Sul. Anais. Disponível em: <http://coloquiomoda. com.br/anais/anais/10-Coloquio-de-Moda_2014/COMUNICACAO-ORAL/CO-EIXO3-CULTURA/COEixo3-VEtA-Um-Estudo-De-Caso.pdf>. Acesso em: 21 fev. 2016.

\section{RAMA, Angel. Transculturación narrativa en América Latina. México: Siglo XXI, 1982.}

SANTOS, Alexandre Ricardo dos. A fotografia e as representações do corpo contido (Porto Alegre 1890-1920). Porto Alegre, 1997. Dissertação (Mestrado em Artes Visuais) - Programa de Pós-Graduação em Artes Visuais, UFRGS, Rio Grande do Sul.

SERRANO, Eneida. Álbum de photographia. Porto Alegre: MCSHJC, 1979.

STUMVOLL, Denise Bujes. Fotografia e aproximações com a arte no início do século XX: um olhar para as narrativas visuais de Lunara. Porto Alegre, 2014. Dissertação (Mestrado em Artes Visuais) Programa de Pós-Graduação em Artes Visuais, UFRGS, Rio Grande do Sul.

ZATTERA, Vera Stédile. Cone Sul: adereços indígenas e vestuário tradicional. Argentina - Brasil - Chile Paraguai - Uruguai. Porto Alegre: Pallotti, 1999.

ZATTERA, Vera Stédile. Gaúcho: iconografia (séculos XIX e XX). Porto Alegre: Pallotti, 1995. 